\title{
Heterogeneity in Multiple Sclerosis: Comparison of Clinical Manifestations in Relatives
}

\author{
A.D. Sadovnick, L.L. Hashimoto and S.A. Hashimoto
}

\begin{abstract}
Once diagnosed to have MS, relatives of persons who have been previously diagnosed frequently ask whether their disease course will follow that of their relative(s) with MS. The present study compared the following clinical manifestations of MS among 43 index cases and 47 of their relatives, all of whom were diagnosed to have MS and regularly attended the MS Clinic in Vancouver, British Columbia: (i) age of onset of MS, (ii) clinical course, (iii) lesion site(s) and (iv) initial symptom(s) of MS. The results from the present study are preliminary because of the small size of the study group. However, these data suggest that apart from possibly age of onset between sibling pairs, the clinical manifestations of MS are not correlated among relatives who are assessed according to the same methodology. This is significant for counselling newly diagnosed relatives of longstanding MS patients.
\end{abstract}

RÉSUMÉ: Hétérogénétié de la sclérose en plaques: comparaison des manifestations cliniques chez des individus apparentés Lorsqu'un diagnostic de SEP est posé chez un individu ayant d'autres cas de la maladie dans sa famille, il est fréquent que cet individu demande si sa maladie va évoluer comme celle des autres membres de sa famille qui en sont atteints. La présente étude compare les manifestations cliniques de la SEP parmi 43 cas index et 47 de leurs parents, tous diagnostiqués comme souffrant de la SEP et qui étaient suivis régulièrement à la clinique de SEP à Vancouver, Colombie Britannique: (i) l'âge de début de la SEP, (ii) l'évolution clinique, (iii) le sit de(s) lésion(s) et (iv) le(s) symptôme(s) de début de la SEP. Les résultats de la présente étude sont préliminaires à cause de la petite taille du groupe étudié. Cependant, ces données suggèrent que, sauf pour l'âge de début de la maladie chez les patients appartenant à une même fratrie, les manifestations cliniques de la SEP ne sont pas corrélées parmi les individus apparentés qui sont évalués en utilisant la même méthodologie. Cette notion est importante pour les patients récemment diagnostiqués qui ont d'autres cas de SEP dans leur famille.

Can. J. Neurol. Sci. 1990: 17: 387-390

Relatives of patients with multiple sclerosis (MS) are often concerned about their risk to also develop the disease. While the exact cause of MS remains unknown, genetic factors play a role in disease susceptibility. Relatives of MS patients therefore have a higher risk of developing MS compared with the general population. ${ }^{1-3}$ Once diagnosed to have MS, relatives of persons who have been previously diagnosed frequently ask whether their disease course will follow that of their relative(s) with MS.

As part of the documentation of genetic family history information collected at the MS Clinic, University Hospital-UBC Site, reportedly affected relatives of index cases are examined whenever possible. However, in the majority of situations, verification of the MS diagnosis is based on a review of clinical and/or autopsy records, obtained with appropriate consent. ${ }^{1,2}$ While these clinical records are sufficient for the purpose of verifying the MS diagnosis in relatives of index cases, they rarely contain sufficient information to allow a detailed profile of the relative's clinical course from disease onset to the present or to time of death. For example, an autopsy report usually provides only neuropathological data.

For all patients attending the MS Clinic, detailed clinical data are collected as far back as the initial onset of symptoms which may have occurred well before the individual came to medical attention. As a result, a detailed clinical profile is obtained for each Clinic patient.

It is therefore preferable to look at whether the clinical manifestations are correlated among relatives by examining data specifically for MS Clinic patients who are related.

\section{METHODOLOGY}

At the time of this study, 2,400 consecutive unrelated index cases have attended the MS Clinic and had detailed family histories taken. Clinical data on related individuals were analyzed for (i) age of onset of MS, (ii) clinical course, (iii) lesion site(s) and (iv) initial symptom(s) of MS.

From the Department of Medical Genetics (A.D.S., L.L.H.) and Multiple Sclerosis Clinic, University Hospital-UBC Site (A.D.S., S.A.H.), University of British Columbia, Vancouver

Received April 6, 1990. Accepted July 24, 1990

Reprint requests to: Dr. A.D. Sadovnick, Dept. of Medical Genetics, University of British Columbia, 6174 University Boulevard, Vancouver, British Columbia, Canada V6T IW5 


\section{Age of Onset of MS}

Age of onset of MS was defined as the age, in retrospect, at which both the patient and MS Clinic neurologist agreed that the first MS symptom(s) occurred. If there was uncertainty, the age of onset was determined by the neurologist, after review of previous clinical records and discussion with the patient. Variance in age of onset among siblings was tested by the F-test and differences in means by the t-test. Similarity in age of onset among relatives was tested by linear regression. The correlation coefficient was considered significant at the $5 \%$ level.

\section{Clinical Course}

MS Clinic criteria separate the clinical course of the disease into the following 4 categories: relapsing-remitting (resolution of acute symptoms with subsequent stabilization), chronic progressive (ongoing chronic deterioration in neurologic function with and without concurrent attacks from onset of MS), relapsingprogressive (an initial relapsing-remitting course becomes chronic progressive over time) and benign (MS duration $\geq 10$ years; Kurtzke Disability Score <3). ${ }^{4}$ In assessing clinical course among relatives, it is crucial to correct for disease duration. This was done by restricting the analysis to relatives with similar disease duration.

\section{Lesion Site(s)}

MS Clinic criteria identify the following lesion site(s): brain stem, spinal cord, cerebral hemispheres, cerebellum and optic nerve. It is common for patients to show lesions at more than one site and some lesions occur more often than others. To control for these factors, the data were analyzed using a modified goodness-of-fix $X^{2}$, incorporating a distance function (R.R. Davidson, Department of Mathematics, University of Victoria, personal communication). In this analysis, a distance of 0 indicates identical lesion site(s) in relatives and a maximum distance of 5 indicates that the relatives have no common lesion site(s). The goodness-of-fit test measured whether the lesion site(s) among relatives differed from the expected distance, based on data for 1,061 unrelated Clinic patients with MS ${ }^{5,6}$ for whom the distribution of lesion sites was analyzed as part of an unpublished study.

\section{Initial Symptom(s) of MS}

Similarity of initial symptom(s) of MS among relatives were analyzed using similar methodology to the analysis of lesion site(s) as there may be more than one initial symptom and some occur more frequently than others. ${ }^{7}$ For the present study, the 15 initial signs recorded by the Clinic were condensed into the following 5 categories by the clinic director (SAH): (1) sensory/l'hermitte sign, (2) motor/bladder, (3) ataxia/balance and/or gait disturbance, (4) optic neuritis and (5) other such as vertigo, diplopia, pain.

\section{RESULTS}

\section{Study Group}

Of the 2,400 consecutive unrelated index cases attending the Clinic, 44 had a total of 50 relatives who also regularly attended the Clinic. Of these relatives, one index case and 3 relatives did not meet the diagnostic criteria for MS, 5.6 resulting in a study group consisting of 43 index cases and 47 of their relatives (Table 1).
Table 1: Pairs of Relatives Concordant for MS Seen at the MS Clinic

\begin{tabular}{lc}
\hline \hline Relative Pairs & Number of Pairs \\
\hline First-degree relatives & 15 \\
Sibling & 12 \\
Parent/child & \\
Second-degree relatives & 4 \\
$\quad$ Aunts-uncles/nieces-nephews & \\
Third-degree relatives & 10 \\
$\quad$ First cousins & 1 \\
$\quad$ Aunt-great niece & 5 \\
More distant relatives & 47 \\
Total: &
\end{tabular}

\section{Age of Onset of MS}

The only comparison which was statistically significant was for age of onset among sibling pairs concordant for MS (Table 2). Variance in age of onset among the index cases was not significantly different from that among their siblings ( $F=1.92$; $p>0.05$ ). The mean age of onset for the index cases was 24.6 years, not significantly greater than the mean age of onset of 28.4 years for their siblings $(t=1.14 ; \mathrm{p}>0.05)$. The correlation coefficient $(r=0.72 ; p<0.005)$ indicated a linear relationship between age of onset among sibling pairs. The slope was 1.00 and the $\mathrm{Y}$ intercept was 3.78 years.

Table 2: Age of MS Onset Among Relatives Concordant for the Disease

\begin{tabular}{lcccc}
\hline \hline $\begin{array}{l}\text { Relative } \\
\text { Pairs }\end{array}$ & $\begin{array}{c}\text { Number of } \\
\text { Pairs }\end{array}$ & Slope & $\begin{array}{c}\text { Correlation } \\
\text { Coefficient }\end{array}$ & Probability \\
\hline Sibling & 15 & 1.000 & 0.722 & $\mathrm{p}<0.005$ \\
Parent/child & 12 & -0.242 & -0.428 & $\mathrm{p}>0.10$ \\
$\begin{array}{l}\text { Second-degree } \\
\begin{array}{l}\text { Third-degree and } \\
\text { more distant } \\
\text { relatives }\end{array}\end{array}$ & 4 & -0.732 & -0.909 & $\mathrm{p}>0.05$ \\
\hline
\end{tabular}

\section{Clinical Course of MS}

Controlling for duration of the MS, it was possible to compare clinical course for 27 pairs of relatives (14 sibling pairs; 4 parent/child pairs; 9 third-degree and more distant relatives). No statistically significant correlation for the clinical course was observed in any of these groups (Table 3 ).

Table 3: Course of MS Among Relatives Concordant for the Disease

\begin{tabular}{lccc}
\hline $\begin{array}{l}\text { Relative } \\
\text { Pairs }\end{array}$ & $\begin{array}{c}\text { Number of } \\
\text { Pairs }\end{array}$ & $\mathbf{X}^{2}$ & Probability \\
\hline Sibling & 14 & 2.57 & $\mathrm{p}>0.75$ \\
Parent/child & 4 & 4.50 & $\mathrm{p}>0.25$ \\
$\begin{array}{l}\text { Second-degree } \\
\begin{array}{l}\text { Third-degree and } \\
\text { more distant } \\
\text { relatives }\end{array}\end{array}$ & 0 & - & - \\
\hline
\end{tabular}




\section{Lesion Site(s) of MS}

As shown in Table 4, no statistically significant similarity in lesion site(s) was observed among relatives concordant for MS.

\begin{tabular}{lccc}
\hline Table 4: Lesion Site(s) Among Relatives Concordant for the MS \\
\hline $\begin{array}{l}\text { Relative } \\
\text { Pairs }\end{array}$ & $\begin{array}{c}\text { Number of } \\
\text { Pairs }\end{array}$ & $\mathbf{X}^{2}$ & Probability \\
\hline Sibling & 15 & 2.17 & $\mathrm{p}>0.50$ \\
$\begin{array}{l}\text { Parent/child } \\
\text { Second-degree }\end{array}$ & 12 & 3.43 & $\mathrm{p}>0.50$ \\
$\begin{array}{l}\text { Third-degree and } \\
\text { more distant } \\
\text { relatives }\end{array}$ & 4 & 1.14 & $\mathrm{p}>0.50$ \\
\hline
\end{tabular}

\section{Initial Symptom(s) of MS}

With the exception of the group of relatives who were thirddegree or more distantly related, no statistically significant correlation of initial symptom(s) was observed among affected relatives (Table 5). The results for the third-degree and more distant relatives category could not be interpreted for the initial symptoms goodness-of-fit test due to small sample size.

Table 5: Initial Symptom(s) Among Relatives Concordant for the MS

\begin{tabular}{lccc}
$\begin{array}{l}\text { Relative } \\
\text { Pairs }\end{array}$ & $\begin{array}{c}\text { Number of } \\
\text { Pairs }\end{array}$ & $\mathbf{X}^{\mathbf{2}}$ & Probability \\
\hline Sibling & 15 & 3.10 & $\mathrm{p}>0.50$ \\
Parent/child & 12 & 0.75 & $\mathrm{p}>0.975$ \\
Second-degree & 4 & 2.29 & $\mathrm{p}>0.50$ \\
\hline
\end{tabular}

\section{Discussion}

The information from this study, while preliminary because of the small sample size, suggests that clinically, MS does not "run true" in families. The data on age of onset of MS suggest a correlation among sibling pairs ( $\mathrm{N}=15$ pairs) but this correlation decreased for other groups of relatives as the degree of the relationship increased. A larger study of Bulman et al ${ }^{8} \mathrm{com}-$ pared age of onset for 99 sibling pairs identified from the MS Clinics in London, Ontario and Vancouver, British Columbia. In this study, age of onset correlations are consistent with random environmental triggers rather than common exposure. The data from the present study differ from those in the study by Bulman et $a^{8}$ in that both members of the sibling pairs were active MS Clinic patients and so, in all cases, age of onset of MS was determined by the actual individual, and not by other family members or by a review of selected medical records.

Weinshenker et al 9 looked at age of MS onset in 7 sibling pairs and 6 parent-child pairs in which both members of the pair regularly attended the MS Clinic in London, Ontario. For this group of first-degree relatives, the intraclass correlation was not significant for age of onset. This data set differed from the one in the present study since age of onset analyses were not done separately for concordant sibling and parent-child pairs.

Schapira et al ${ }^{10}$ and more recently Bulman et al ${ }^{8}$ discussed the fact that correlation in age of onset of MS for concordant sibling pairs provides more evidence for the role of genetics in disease susceptibility. The age difference among sibling pairs is an important consideration. "Common exposure" must be considered when sibling pairs are close in age 11.12 as, unlike relatives in different generations or sibling pairs who are separated by $\geq 5$ years, these individuals may share a common environment and so be exposed to a "triggering agent" at a similar point in time. In the present study, 10 of the sibling pairs were 4 years or less apart in age and the remaining 5 varied from 5 to 16 years, with a mean of 8.6 years.

Correlation in age of onset of MS is low for parent-child pairs, with parents tending to report an older age of onset than do their children. There are several possible explanations for this. Lack of "common exposure" must of course be a consideration. Another possible explanation for this observation is "anticipation", i.e. the progressively younger age of onset among subsequent generations. This has been observed, for example, in myotonic dystrophy. 13 "Anticipation" is believed to be an artifact rather than biologically significant. Other explanations which more probably explain the different results for sibling and parent-child pairs include the fact that age of onset is defined retrospectively and it is of course necessary for parents to recall events in the much more distant past than their children. In addition, parents with MS are often concerned that their children will also develop the disease and so when MS-like symptoms occur in a child, there will be more pressure on that child to seek medical attention at an early stage and with a positive family history, the physician is more likely to make the diagnosis of MS early.

In the present study, clinical course, site of lesion(s) and initial symptom(s) among relatives concordant for MS were not correlated. In addition, Weinshenker et al, ${ }^{9}$ in their group of 13 concordant first-degree relative pairs, did not find significant intraclass correlation in clinical course (only comparing relapsing-remitting with chronic progressive from the onset of MS), number of attacks in the first 2 years of the disease, the interval between a first and second attack and the time to reach last common Kurtzke Disability Status Scale. The results from these 2 studies are compatible in that they provide independent evidence that the clinical manifestations of MS are not similar among affected relatives. This information is important for counselling affected relatives with respect to prognosis. In addition, if the clinical manifestations were similar among relatives, there would be implications for treatment and preventative measures. As well, if MS were found to "run true" in families, one could possibly identify discrete familial subsets which might provide clues to the etiology of MS within some families.

In conclusion, although the data from the present study and those of Weinshenker et al $^{9}$ are preliminary because of the small size of the study groups, they provide the first objective information on clinical manifestations of MS among pairs of relatives concordant for MS in which both members of the pair are being actively evaluated at an MS clinic.

\section{ACKNOWLEDGEMENTS}

The authors would like to thank the following members of the MS Clinic, University Hospital-UBC Site: Dr. DW Paty (Research Director and Neurologist), Drs. J. Hooge, L. Kastrukoff, J-F Oger (Neurologists) and Mrs. K. Eisen (Clinic Coordinator). The help of M. Irwin, I. Yee and R.R. Davidson with the statistical analyses is greatly appreciated. This study was funded in part by the Multiple Sclerosis Society of Canada, B.C. Division. 


\section{REFERENCES}

1. Sadovnick AD, Baird PA. The familial nature of multiple sclerosis: age-corrected empiric risks for children and siblings of patients. Neurology 1988; 38: 990-991.

2. Sadovnick AD, Baird PA, Ward RH. Multiple sclerosis: updated risks. Am J Med Genet 1988; 29: 533-541.

3. Ebers GC, Bulman DE, Sadovnick AD, et al. A population based twin study in multiple sclerosis. N Engl J Med 1986; 315: 16381642.

4. Kurtzke JF. Rating neurological impairment in multiple sclerosis: an expanded disability status scale (EDSS). Neurology 1983; 33: $1444-1452$

5. Schumacher GA, Beebe G, Kibler RF, et al. Problems of experimental trials of therapy in multiple sclerosis: report of the panel on the evaluation of experimental trials of therapy in multiple sclerosis. Ann NY Acad Sci 1965; 122: 552-568.

6. Poser CM, Paty DW, Scheinberg L, et al. New diagnostic criteria for multiple sclerosis. Guidelines for research protocols. In: Poser CM, Paty DW, Scheinberg L, Ebers GC, eds. The Diagnosis of Multiple Sclerosis. New York: Thieme-Stratton 1984; 225-229.

7. Weinshenker B, Bass B, Rice GPA, et al. The natural history of multiple sclerosis: a geographically based study. 1. Clinical course and disability. Brain 1989; 112: 133-146.
8. Bulman DE, Sadovnick AD, Cripps J, et al. Age of onset in siblings concordant for multiple sclerosis. (Submitted.) Summary in Gonatas NK, Greene MI, Waksman BH. Genetic and Molecular Aspects of Demyelination. Immunology Today 1986; 7: 121126.

9. Weinshenker B, Armstrong $\mathrm{H}$, Bulman D, et al. A comparison of familial and sporadic MS. Can J Neurol Sci 1986; 13 (Abstract): 168.

10. Schapira K, Poskanzer DC, Miller H. Familial and conjugal multiple sclerosis. Brain 1963; 86: 315-332.

11. Kurtzke JF. Epidemiological contribution to MS: an overview. Neurology 1980; 30: 61-79.

12. Kurtzke JF, Hyllested K. Multiple sclerosis in the Faroe Islands: 1. Clinical and epidemiological features. Ann Neurol 1979; 5:621 .

13. Harper PS. Myotonic dystrophy. Philadelphia: WB Saunders 1979; 10: 219-223.

14. Kurtzke JF. On the evaluation of disability in multiple sclerosis. Neurology 1961; 11: 686-694. 